\title{
PRIETZEL, Malte, Krieg im Mittelalter
}

\section{Xavier Hélary}

\section{OpenEdition \\ Journals}

Édition électronique

URL : http://journals.openedition.org/ifha/573

DOI : 10.4000/ifha.573

ISSN : 2198-8943

Éditeur

IFRA - Institut franco-allemand (sciences historiques et sociales)

\section{Référence électronique}

Xavier Hélary, "PRIETZEL, Malte, Krieg im Mittelalter», Revue de l'IFHA [En ligne], Date de recension, mis en ligne le 01 janvier 2007, consulté le 22 septembre 2020. URL : http://journals.openedition.org/ifha/ 573 ; DOI : https://doi.org/10.4000/ifha. 573

Ce document a été généré automatiquement le 22 septembre 2020.

(CIFHA 


\title{
PRIETZEL, Malte, Krieg im Mittelalter
}

\author{
Xavier Hélary
}

Les historiens de la guerre doivent encore souvent justifier l'intérêt de leur objet d'étude, souvent ramené à une " histoire militaire » à la réputation douteuse, ou, pire encore, à la fameuse " histoire bataille ". Avec ces deux ouvrages parus en 2006, M.P. administre la preuve de l'étonnante vigueur de l'histoire de la guerre - fort loin des lieux communs qui s'expriment encore à ce sujet, particulièrement en France. À partir des années 70, plusieurs historiens de haut vol se sont penchés sur la constitution et les modalités de recrutement des armées médiévales : celles des rois de France pendant la guerre de Cent Ans (Philippe Contamine, 1972), celles du roi d'Angleterre Édouard Ier (Michael Prestwich, 1972), celles Charles d'Anjou, premier roi de Sicile (Joachim Göbbels, 1979) ; l'ouvrage récent de S. Boffa, à propos des armées des ducs de Brabant au tournant des XIVe et XVe s. (2004) a montré la richesse toujours féconde des principes posés par cette histoire sociale des armées qui, au moins dans le cas de Philippe Contamine, prenait son inspiration dans la démarche de l'École des Annales. C'est un autre aspect de cette histoire renouvelée de la guerre auquel M.P. s'intéresse ici. L'ouvrage est divisé en deux parties chronologiques : la première couvre les IXeXIIe s., la seconde la fin du Moyen Âge, et plus précisément la guerre de Cent Ans. Toute la chrétienté occidentale est envisagée, avec une attention plus particulière à l'espace français, surtout dans la deuxième partie. L'objectif est de jeter un éclairage différent sur les récits de toute nature qui nous renseignent sur la pratique de la guerre des hommes du Moyen Âge : c'est moins cependant le warfare cher aux Anglo-Saxons que tout ce qu'il y a autour de la guerre et de la bataille. Dans cette perspective, l'auteur se penche sur ce qui précède le combat : les fanfaronnades, les provocations, les escarmouches et la valorisation du duel devenu combat idéal ; et sur ce qui suit le combat : l'occupation du champ de bataille, le sort des vaincus et la mise au point d'un récit (combien de morts?), la diffusion de la nouvelle de la victoire ; la solidarité dans la mort, aussi. Au total, c'est en somme autant une histoire des enjeux symboliques de la guerre que de la guerre elle-même : très logiquement, l'honneur y prend une place importante. Ce faisant, l'auteur rend aux sources (très nombreuses) qu'il utilise leur véritable nature de construction intellectuelle ou mémorielle, en mettant au jour les récurrences qui, dans chacune des deux périodes qu'il a dégagées, comme de façon 
transversale, se retrouvent dans la façon qu'ont les hommes du Moyen Âge de raconter la guerre et la bataille. À la fin de chacune des deux parties, une attention particulière est dévolue aux enseignes, étendards et autres signes de distinction utilisés par les combattants.

Le second ouvrage de M.P. est d'un format très différent : il a pour objectif de donner au grand public cultivé un aperçu de la guerre en Europe (surtout en France et en Allemagne) au Moyen Âge (du VIIIe au XVe s.). Une très riche illustration (cartes, enluminures, pièces d'armures, fortifications) sert un texte toujours synthétique et limpide. Les différents aspects de la guerre médiévale sont traités de manière très pertinente, en mettant toujours en évidence les évolutions : ainsi le recrutement des armées, l'idéologie de la guerre, la propagande, la croisade, les fortifications, les destinées de la chevalerie. Le lecteur français sera particulièrement intéressé par deux thèmes peu traités par l'historiographie française : la participation des villes à la guerre (chapitre VIII) et " guerre et politique dans l'Allemagne de la fin du Moyen Âge ». Les titres essentiels sont cités dans une courte bibliographie.

Particulièrement dynamique dans les pays anglo-saxons, l'histoire de la guerre reçoit donc ici une double contribution très importante.

Xavier HELARY (Université Paris-Sorbonne - Paris IV) 